International Journal of Agriculture, Environment and Bioresearch

Vol. 5, No. 06; 2020

ISSN: $2456-8643$

\title{
SUITABILITY ASSESSMENT OF ORANGE FLESHED SWEETPOTATO VARIETIES AT NORTHERN REGION OF BANGLADESH
}

\author{
M.M. Hossain ${ }^{1}$, S. Heck ${ }^{1}$, D. Chanda ${ }^{1}$, E.H.M.S. Rahaman ${ }^{1}$, M.F. Uddin ${ }^{1}$, M.M. Hasan ${ }^{2}$ and M.H. Kabir $^{3}$ \\ ${ }^{1}$ International Potato Center, Banani, Dhaka, Bangladesh, \\ ${ }^{2}$ Gana Unnayan Kendra (GUK), Gaibandha, Bangladesh and \\ ${ }^{3}$ Sher-E-Bangla Agricultural University, Sher-E-Bangla Nagar, Dhaka, Bangladesh
}

https://doi.org/10.35410/IJAEB.2020.5597

\begin{abstract}
The present experiment was conducted with four Bangladesh Agricultural Research Institute (BARI) released orange fleshed sweetpotato varieties and a local cultivar as check at Sadar Upazila of Gaibanda and Pirgachha Upazila of Rangpur district during 2019-20 cropping season for their suitability assessment. It was found that all yield and yield contributing characters varied significantly at both the locations. Due to higher adaptability in northern conditions, it was observed that the variety of BARI SP-12 produced the highest yield (39.63 ton/ha at Gaibandha and $30.02 \mathrm{t} / \mathrm{ha}$ at Rangpur) followed by BARI SP-8 (32.03 ton/ha at Gaibandha and 25.93 t/ha at Rangpur) while the lowest was recorded in BARI SP-15 (13.33 ton/ha at Gaibandha and 3.03 ton/ha at Rangpur). Considering locations, all the studied varieties performed better at Gaibandha than Rangpur district. The crop was evaluated at vegetative and harvesting stage at farmers' field by the farmers, researchers and extension staffs. At harvesting stage evaluation results revealed that, BARI SP-8 ranked first at Gaibandha and BARI SP-12 at Rangpur while BARI SP-4 ranked (2nd) at both locations. During harvesting stage evaluation, participants preferred BARI SP-12 as at both locations followed by BARI SP-8 at Gaibandha and BARI SP-4 at Rangpur. Through organoleptic test BARI SP-4 and BARI SP-12 found good to excellent by the farmers, researchers and extension staffs.
\end{abstract}

Keywords: Sweet potato, evaluation, organoleptic test.

\section{INTRODUCTION}

Sweetpotato (Ipomoea batatus), is an important staple crop in many parts of the world (Rahaman et al. 2015). It is a dicotyledonous plant that belongs to the Convolvulaceae family is also an important starch rich root crops in Bangladesh. The foliage has the potential for use as vegetable and animal feed (Otoo et al., 2001). Worldwide, sweetpotato is the sixth most vital food crop after rice, wheat, potatoe, maize and cassava and for developing countries, it is in the fifth place. More than 105 million metric tons are produced globally each year; 95\% of which are grown in developing countries (Anonymous, 2020). It is mainly cultivated by the marginal or subsistence farmers in a sporadic way in different river belts, char lands, deltas and seasonally inundated flood plains (Ahmed et al., 1998). The average yield is very low as compare to many tropical to subtropical countries due to cultivation of local and poor quality indigenous sweetpotato varieties. (Vimala and Rajendra, 1998). 
Vol. 5, No. 06; 2020

ISSN: $2456-8643$

Bangladesh ranks 88th out of 117 qualifying countries on the latest (2019) Global Hunger Index, much ahead of India, Pakistan and Afghanistan. Bangladesh reduced hunger significantly, but with a score of 25.8, the country still suffers from a level of hunger that is serious (bdnews.com, 2019).

Prevalence of malnutrition in Bangladesh is still alarming and it is even higher than countries like, Nepal, Cambodia, Ethiopia and Uganda. Bangladesh is placed in the bottom 25\% of the Global Hunger Index (Anonymous, 2015). Under-nutrition in Bangladesh is among the highest in the world and remains a serious public health problem. Approximately 9 million Bangladeshi children between six months and five years of age (pre-school going age) suffer from undernutrition, with 36 percent of children stunted, 33 percent of children underweight, and 14 percent wasted (NIPORT, 2016). Bangladeshi children also suffer from high rates of micronutrient deficiencies, particularly vitamin A, iron, iodine and zinc deficiency. Bangladesh should be commended for making significant progress in reducing vitamin A deficiency (VAD) among preschool children over the past 15 years; however, consumption of vitamin A rich foods is still low. Malnutrition among women is also extremely prevalent in Bangladesh. More than 50 percent of women suffering from chronic energy deficiency. A quarter of women population are underweight and around $15 \%$ have short stature, which increases the risk of difficult childbirth and low-birth weight infants. Half of all women suffer from anemia, mostly nutritional in origin (ICDDR'B, 2020). Clinical VAD is common among women of reproductive age and during pregnancy. Sub-clinical VAD and anemia are also highly prevalent among pregnant and lactating women.

Improving nutrition can have a significant impact on survival as well as physical and cognitive development and productivity (FAO,2010). Good nutrition, comprising adequate quality and quantity of food intake and reduction of illness is also a basic human right and is an essential input for economic development. Significant progress has been made in cereal production in Bangladesh over the past decades. However, the rapid population growth and resulting high and growing food requirements pose a difficult challenge given the limited availability of cultivable land in Bangladesh. Re-occurring disasters further complicate the stability of food production. Monga is a common phenomenon in the northwestern part of Bangladesh and food insecurity and nutritional problem are more severe in this area compare to other parts of Bangladesh (Karim and Tasnim, 2015). The farmers of northern regions of Bangladesh cultivated white fleshed local sweetpotato varieties despite of lower yield and very low nutritional benefits. There is a clear need to diversify food sources both in terms of land/environmental sustainability, development of the rural economy and increased consumption to achieve improvements in the nutritional status of the people of Bangladesh.

Orange fleshed sweetpotato is a biofortified food crops as it contained beta carotene with a good source of vitamin B, C, E and other minerals (Rahaman et al. 2016). It is a highly nutritious food crop which gives better and faster production under diverse agroecological conditions with less input and that has immense potential to combat malnutrition and poverty (CIP, 2008). To combat malnutrition, vitamin A deficiency and ensure food security, orange fleshed sweetpotato (OFSP) could be one of the best options for agricultural production. 
Since 1985, TCRC, BARI has released 16 high yielding sweetpotato varieties in Bangladesh. But dissemination rate of those varieties among the farmers in different agro-ecological zones is not in wide range due to limited promotional activities had been undertaken by different organizations. Considering this point of view, an adaptive trial of four BARI released OFSP varieties has been undertaken at two farmers' fields to identify some suitable varieties which will be accepted by the farmers of northern districts of Bangladesh.

\section{MATERIALS AND METHODS}

The present experiment was carried out at Sadar Upazila (sub-district) of Gaibandha and Pirgachha Upazila of Rangpur districts during 2019-20 cropping season. Four BARI released sweetpotato varieties viz. BARI SP- 4, BARI SP-8, BARI SP-12 and BARI SP-15 along with a local cultivar as check were included in this study. Vines were collected from TCRC, BARI and planted on 26 November 2019 at Sadar, Gaibandha and 15 December 2020 at Pirgachha, Rangpur, having plot size of $3.0 \mathrm{~m} \times 3.0 \mathrm{~m}$ with 3 replications following Randomized Complete Block Design (RCBD). Fertilizers were applied in the experimental plots at the rate of 70-25-90$15-2-2 \mathrm{~kg} / \mathrm{ha}$ of N-P-K-S-B-Zn as a source of Urea, TSP, MP, Gypsum, Boric Acid and Zinc Sulphate, respectively. Weeding, irrigation, earthing-up and other intercultural operations were done as and when necessary. The sweetpotato was harvested on 25 March 2020 and 14 April 2020 at Sadar, Gaibandha and Pirgachha, Rangpur, respectively. Physio-morphological characteristics of sweet potato roots of studied varieties are presented in Table 1.

Table 1. Root characteristics of BARI released four OFSP varieties

\begin{tabular}{|l|l|l|l|c|c|}
\hline Variety & Shape and size & Skin color & Flesh color & $\begin{array}{l}\text { B-carotene content } \\
(\mathrm{mg} / 100 \mathrm{~g} \text { fresh wt. })\end{array}$ & $\begin{array}{l}\text { Dry Matter } \\
(\%)\end{array}$ \\
\hline BARI SP-4 & Round elliptic & Orange brown & Orange & 4.8 & 27.00 \\
\hline BARI SP-8 & Round elliptic & Purple Red & Inter. yellow & 1.1 & 35.30 \\
\hline BARI SP-12 & Long elliptic & Brownish & Pink Orange & 3.6 & 35.44 \\
\hline BARI SP-15 & Round elliptic & Orange & Deep Orange & 10.39 & 30.39 \\
\hline
\end{tabular}

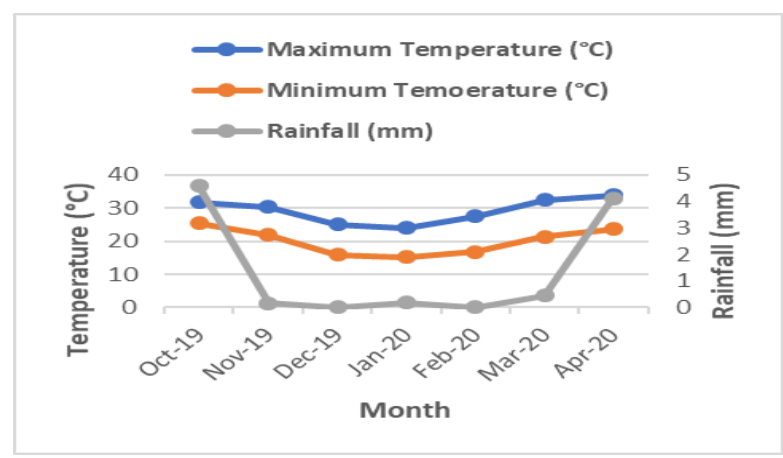

At Gaibandha

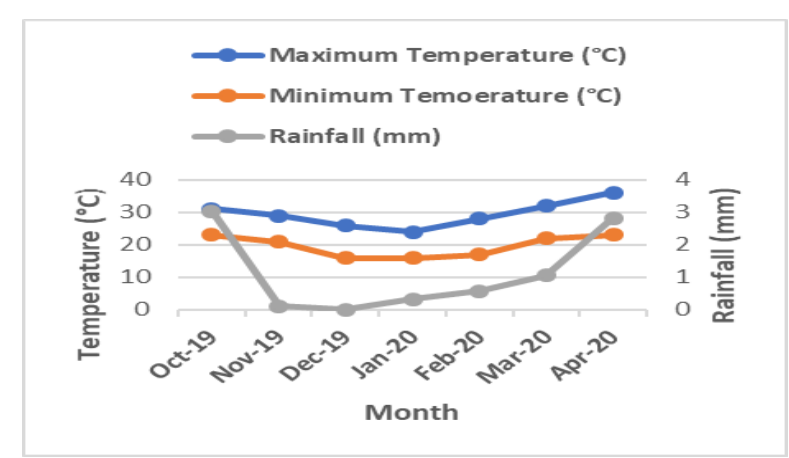

At Rangpur

Fig. 1. Average maximum and minimum temperature with rainfall at Gaibandha and Rangpur during 2019-20 cropping season 
All the studied sweet potato varieties were evaluated in vegetative and harvesting stages following PVS method developed by Staff de Hann of CIP (Wangchuk et al., 2015). After 90 days of planting, vegetative stage evaluation was done. Harvesting stage evaluation followed by organoleptic evaluation were done at 120 DAP. During evaluations, the following steps were performed:

\section{Step 1: Evaluation at the time of vegetative stage}

a) Gathering and Ranking of Criteria

b) Ranking of the preferred varieties by plot

\section{Step-2: Evaluation at the time of harvesting stage}

a) Gathering and Ranking of Criteria

b) Ranking of the preferred varieties by plot

\section{Step-3: Organoleptic/Sensory evaluation}

Before evaluation of each stage (Vegetative and harvest), the method was explained properly. For the evaluation, a panel of fifteen participants ( 5 male farmers, 5 female farmers and 5 researchers \& extension personnel's) were made. The participants of the group provided their opinions to select best varieties. Due to COVID-19 situation, all farmers, researchers and staffs were instructed to wear masks and use sanitizers in field and maintained social distancing.

For giving votes, two different types of seeds had been provided to the participants for segregating male or female participants. Six seeds were given each individual for voting. Among them, three seeds were used for first priority vote, two for second and one for third position for each criterion. Only three criteria/varieties they had to choose in all phases of evaluation. After computation of votes, it was termed as global score. According to global score order of importance was made, and first three characters/varieties were selected.

\section{Step 1: Evaluation at the time of vegetative stage}

At vegetative stage, first of all the participants mentioned some criteria which they wanted to be in the upcoming sweetpotato varieties. All the criteria were listed, and individual voting had been made for the specific characters. After voting, three criteria were selected on the basis of the highest score. After selection the criteria, participants visited the sweetpotato field and observed the vegetative growth stage of the varieties. After observation, all participants had given their votes to select three varieties.

\section{Step-2: Evaluation at the time of harvesting stage}

At the time of harvest, again fifteen participants were gathered and initially selected some harvesting stage criteria which they are expecting in the upcoming variety. Then they had given 
their votes to select the best three harvesting criteria from the initially selected criteria. After criteria selection, all the participants visited the harvested field of sweet potato and observed yield and tuberous root characters. After observation, they gave their opinions as a vote for best three varieties.

\section{Step-3: Organoleptic/Sensory evaluation}

After harvesting stage evaluation an organoleptic evaluation was performed. For this one kilogram of sweet potatoes from each variety was boiled, separated the varieties on different plates and clearly identified by registration number. The basic rules of evaluation were explained to the participants using simple words.

a. Appearance: The appearance refers to the visual aspect: how the boiled sweet potato varieties looks when presented on plates (Scale 5=Very good, 4=Good, 3=Fair, 2=Poor and $1=$ Very Poor)

b. Flesh color: After cross section of boiled sweet potato, how the flesh color looks of each variety (Scale 5=Very good, $4=$ Good, $3=$ Fair, $2=$ Poor and $1=$ Very Poor)

c. Taste: The taste is very personal criterion (Scale $5=$ Very good, $4=$ Good, $3=$ Fair, $2=$ Poor and $1=$ Very poor)

d. Texture: The texture refers to the dry matter that the sweetpotatoes possess (Scale 5=Mealy/Floury, 4=Less floury, 3=Fair/Intermediate, 2=Soggy and 1= More soggy/watery)

e. Fiber: The fiber refers to the presence of fiber in boiled sweetpotato flesh (Scale $5=$ No fiber presence, 4=Less fiber presence, 3=Fair/moderate fiber presence, 2=Poor/high presence of fiber and $1=$ Roots are fibrous)

Each panellist was given an evaluation form which was used to record the evaluation in reference to the appearance, flesh color, taste, texture and fiber of each variety. Each panellist evaluated clone by clone and washed his/her mouth with mineral water before moving on to the next sample.

\section{RESULTS AND DISCUSSION}

From the combined analysis of variance (ANOVA) table, it was observed that plant vigor at 90 DAP (Days After Planting), number of tuberous root per plant, tuberous root diameter, tuberous root yield per plant, tuberous root yield per plot and yield (ton/ha) varied significantly over the location (Table 2). Effects of variety showed significant variation for all the growth and yield contributing characters of the crops. Considering location and variety (LxV) interaction effects, most of the characters varied significantly except plant vigor at $90 \mathrm{DAP}$, percent foliage coverage at $60 \mathrm{DAP}$, tuberous root yield per plot, yield ton per hectare and dry matter percentage of root (Table 2). 
Table 2. Combined analysis of variance (ANOVA) of yield and yield contributing characters of sweetpotato over locations

\begin{tabular}{|l|c|l|l|l|l|l|l|}
\hline \multirow{2}{*}{$\begin{array}{c}\text { Source of } \\
\text { variation }\end{array}$} & \multirow{2}{*}{$\mathbf{d f}$} & $\begin{array}{l}\text { Vine length } \\
\text { (cm) at 60 } \\
\text { DAP }\end{array}$ & $\begin{array}{l}\text { Vine length } \\
\text { (cm) at 90 } \\
\text { DAP }\end{array}$ & $\begin{array}{l}\text { Vine length } \\
\text { (cm) at 120 } \\
\text { DAP }\end{array}$ & $\begin{array}{l}\text { Plant } \\
\text { vigor at } \\
\text { 60 DAP }\end{array}$ & $\begin{array}{l}\text { Plant } \\
\text { vigor at } \\
\text { 90 DAP }\end{array}$ & $\begin{array}{l}\text { Foliage } \\
\text { Coverage (\%) } \\
\text { at 60 DAP }\end{array}$ \\
\hline Location (L) & 1 & $135.25 \mathrm{NS}$ & $14.70 \mathrm{NS}$ & $369.60 \mathrm{NS}$ & $1.63 \mathrm{NS}$ & $4.03 *$ & $83.33 \mathrm{NS}$ \\
\hline Error-1 & 4 & 84.48 & 88.69 & 141.44 & 0.37 & 0.26 & 173.33 \\
\hline Variety (V) & 4 & $701.18^{* *}$ & $1887.47 * *$ & $5277.03 * *$ & $6.58^{* *}$ & $6.47 * *$ & $1690.42^{* *}$ \\
\hline L X V & 4 & $322.73^{* *}$ & $852.27 * *$ & $1767.17^{* *}$ & $1.22^{*}$ & $0.18 \mathrm{NS}$ & $31.25 \mathrm{NS}$ \\
\hline Residual & 16 & 39.31 & 41.23 & 94.62 & 0.33 & 0.14 & 29.58 \\
\hline
\end{tabular}

Table 2. cont'd.

\begin{tabular}{|l|c|c|c|l|c|c|c|}
\hline & & & \multicolumn{5}{|c|}{ Error Mean Square } \\
\cline { 3 - 8 } $\begin{array}{c}\text { Source of } \\
\text { variation }\end{array}$ & df & $\begin{array}{l}\text { Foliage } \\
\text { Coverage } \\
(\%) \text { at 90 } \\
\text { DAP }\end{array}$ & $\begin{array}{l}\text { Foliage } \\
\text { Coverage } \\
(\%) \text { at 120 } \\
\text { DAP }\end{array}$ & $\begin{array}{l}\text { No. Branches } \\
\text { /plant at 90 } \\
\text { DAP }\end{array}$ & $\begin{array}{l}\text { No. Branches } \\
\text { /plant at 120 } \\
\text { DAP }\end{array}$ & $\begin{array}{l}\text { No. of } \\
\text { tuberous } \\
\text { roots/plant }\end{array}$ & $\begin{array}{l}\text { Tuberous } \\
\text { root length } \\
\text { (cm) }\end{array}$ \\
\hline Location (L) & 1 & $213.33 \mathrm{NS}$ & $20.83 \mathrm{NS}$ & $2.13 \mathrm{NS}$ & $2.58 \mathrm{NS}$ & $30.60^{* *}$ & $12.81 \mathrm{NS}$ \\
\hline Error-1 & 4 & 63.33 & 30.83 & 0.92 & 1.00 & 0.83 & 8.53 \\
\hline Variety (V) & 4 & $3532.08^{* *}$ & $1936.67^{* *}$ & $8.27^{* *}$ & $8.96^{* *}$ & $1.60^{* *}$ & $11.61^{*}$ \\
\hline L X V & 4 & $419.58^{* *}$ & $66.67^{*}$ & $5.45^{* *}$ & $5.09^{* *}$ & $1.81^{* *}$ & $12.04^{*}$ \\
\hline Residual & 16 & 38.33 & 17.29 & 0.65 & 0.83 & 0.32 & 2.91 \\
\hline
\end{tabular}

Table 2. cont'd.

\begin{tabular}{|c|c|c|c|c|c|c|}
\hline \multirow[b]{2}{*}{$\begin{array}{c}\text { Source of } \\
\text { variation }\end{array}$} & \multirow[b]{2}{*}{ df } & \multicolumn{5}{|c|}{ Error Mean Square } \\
\hline & & $\begin{array}{l}\text { Tuberous root } \\
\text { diameter }(\mathbf{c m})\end{array}$ & $\begin{array}{l}\text { Tuberous roots } \\
\text { yield/plant (gm) }\end{array}$ & $\begin{array}{l}\text { Tuberous root } \\
\text { yield (Kg/Plot) }\end{array}$ & $\begin{array}{l}\text { Tuberous root } \\
\text { yield (ton/ha) }\end{array}$ & $\begin{array}{c}\text { Dry Matter } \\
(\%)\end{array}$ \\
\hline Location(L) & 1 & $30.20^{* *}$ & $308053.33^{* *}$ & $613.82 * *$ & $758.02 * *$ & $6.63 \mathrm{NS}$ \\
\hline Error-1 & 4 & 1.18 & 6080.83 & 16.75 & 20.57 & 1.91 \\
\hline Variety (V) & 4 & $34.66^{* *}$ & $138995.00^{* * *}$ & $518.10^{* * *}$ & $640.18^{* *}$ & $23.16^{* * *}$ \\
\hline L X V & 4 & $12.27 * *$ & $20870.00 *$ & $7.72 \mathrm{NS}$ & $9.62 \mathrm{NS}$ & $2.25 \mathrm{NS}$ \\
\hline Residual & 16 & 0.93 & 5997.50 & 5.99 & 7.42 & 2.35 \\
\hline
\end{tabular}

Note: ' ${ }^{\prime}$ ' and ' $* *$ ' indicate statistically significant at $5 \%$ and $1 \%$ level respectively.

Vine length at $60,90 \& 120$ DAP varied significantly in both the locations. At Gaibandha, the highest vine length was found in BARI SP-8 $(42.40 \mathrm{~cm}$ at 60 DAP, $72.50 \mathrm{~cm}$ at 90 DAP and $140.53 \mathrm{~cm}$ at 120 DAP ) followed by BARI SP-4 $(32.70 \mathrm{~cm}$ at $60 \mathrm{DAP}, 62.73 \mathrm{~cm}$ at 90 DAP and $121.47 \mathrm{~cm}$ at $120 \mathrm{DAP})$ and the lowest was observed in local variety $(21.83 \mathrm{~cm}$ at $60 \mathrm{DAP}, 31.67$ $\mathrm{cm}$ at 90 DAP and $62.17 \mathrm{~cm}$ at 120 DAP). At Rangpur, the variety BARI SP-8 also exhibited highest vine length $(53.07 \mathrm{~cm}$ at $60 \mathrm{DAP}, 75.96 \mathrm{~cm}$ at $90 \mathrm{DAP}$ and $128.97 \mathrm{~cm}$ at $120 \mathrm{DAP}$ ) followed by local variety $(46.73 \mathrm{~cm}$ at $60 \mathrm{DAP}, 66.43 \mathrm{~cm}$ at $90 \mathrm{DAP}$ and $106.46 \mathrm{~cm}$ at 120 DAP) and the lowest was recorded in BARI SP-15 $(12.17 \mathrm{~cm}$ at $60 \mathrm{DAP}, 18.63 \mathrm{~cm}$ at 90 DAP and $32.90 \mathrm{~cm}$ at 120 DAP )(Table 3). These may be happened due to adaptability of northern climatic condition. 
ISSN: $2456-8643$

Table 3. Vine length of studied OFSP varieties at 60, 90 and 120 DAP at Gaibandha and Rangpur district of Bangladesh during 2019-2020 crop season

\begin{tabular}{|c|c|c|c|c|c|c|c|c|c|}
\hline \multirow[t]{2}{*}{ Variety } & \multicolumn{2}{|c|}{$\begin{array}{l}\text { Vine Length at } \\
60 \text { DAP }(\mathrm{cm})\end{array}$} & \multirow[t]{2}{*}{ Avg. } & \multicolumn{2}{|c|}{$\begin{array}{l}\text { Vine Length at } \\
90 \text { DAP }(\mathrm{cm})\end{array}$} & \multirow[t]{2}{*}{ Avg. } & \multicolumn{2}{|c|}{$\begin{array}{l}\text { Vine Length at } \\
120 \text { DAP }(\mathrm{cm})\end{array}$} & \multirow[t]{2}{*}{ Avg. } \\
\hline & Gaibandha & Rangpur & & Gaibandha & Rangpur & & Gaibandha & Rangpur & \\
\hline BARI-SP-4 & $32.70 \mathrm{ab}$ & $29.97 b$ & 31.34 & $62.73 a$ & $38.47 \mathrm{~b}$ & 50.60 & $121.47 b$ & $98.03 b c$ & 109.75 \\
\hline BARI-SP-8 & $42.40 \mathrm{a}$ & $53.07 \mathrm{a}$ & 47.74 & $72.50 \mathrm{a}$ & $75.96 a$ & 74.23 & $140.53 a$ & $128.97 \mathrm{a}$ & 125.22 \\
\hline BARI-SP-12 & $23.33 b c$ & $25.97 b$ & 24.65 & $32.70 \mathrm{~b}$ & $33.47 \mathrm{~b}$ & 33.09 & $80.43 c$ & $84.00 \mathrm{c}$ & 82.22 \\
\hline BARI-SP-15 & $26.40 \mathrm{bc}$ & $12.17 \mathrm{c}$ & 19.29 & $40.37 b$ & $18.63 \mathrm{c}$ & 25.00 & $80.87 \mathrm{c}$ & $32.90 \mathrm{~d}$ & 56.89 \\
\hline Local variety & $21.83 \mathrm{c}$ & $46.73 a$ & 34.28 & $31.67 \mathrm{~b}$ & $66.43 \mathrm{a}$ & 49.05 & $62.17 \mathrm{~d}$ & $106.46 \mathrm{~b}$ & 84.32 \\
\hline Mean & 29.33 & 33.58 & 31.46 & 47.99 & 44.79 & 46.39 & 93.28 & 90.07 & 91.68 \\
\hline CV (\%) & & 19.93 & & & 13.58 & & & 10.39 & \\
\hline
\end{tabular}

Note: Means with the same letter are not significantly different

Plant vigor was varied significantly at 60 and 90 DAP in both the locations. At 60 DAP, the highest plant vigor (4.67) was observed in BARI SP-8 at both locations while the lowest was found in BARI SP-15 (2.67 at Gaibandha and 1.00 at Rangpur). At 90 DAP, the local variety showed the highest vigorous growth (4.83) followed by BARI SP-8 (4.67) at Gaibandha and in Rangpur, BARI SP-8 and local variety exhibited high vigorous growth (4.00). On the other hand, the lowest vigorous growth was observed in BARI SP-15 in both the locations (2.33 at Gaibandha and 1.33 at Rangpur) (Table 4). These may be happened due to varietal characteristics.

Table 4. Plant vigor sweetpotato at 90 and 120 DAP at Gaibandha and Rangpur district of Bangladesh during 2019-2020 crop season

\begin{tabular}{|c|c|c|c|c|c|c|}
\hline \multirow{2}{*}{ Variety } & \multicolumn{2}{|c|}{ Plant Vigor at 60 DAP } & \multirow{2}{*}{ Avg. } & \multicolumn{2}{|c|}{ Plant Vigor at 90 DAP } & \multirow{2}{*}{ Avg. } \\
\hline & Gaibandha & Rangpur & & Gaibandha & Rangpur & \\
\hline BARI-SP-4 & $3.67 b$ & $3.33 b$ & 3.50 & $4.00 \mathrm{~b}$ & $3.00 c$ & 3.50 \\
\hline BARI-SP-8 & $4.67 \mathrm{a}$ & $4.67 \mathrm{a}$ & 4.67 & $4.67 a$ & $4.00 a$ & 4.34 \\
\hline BARI-SP-12 & $3.67 \mathrm{~b}$ & $4.33 \mathrm{a}$ & 4.00 & $3.67 b$ & $3.50 \mathrm{~b}$ & 3.59 \\
\hline BARI-SP-15 & $2.67 \mathrm{c}$ & $1.00 \mathrm{c}$ & 1.84 & $2.33 c$ & $1.33 d$ & 1.83 \\
\hline Local variety & $4.00 \mathrm{ab}$ & $3.00 \mathrm{~b}$ & 3.50 & $4.83 a$ & $4.00 a$ & 4.42 \\
\hline Mean & 3.74 & 3.26 & 3.50 & 3.90 & 3.17 & 3.53 \\
\hline CV (\%) & \multicolumn{2}{|c|}{16.29} & & \multicolumn{2}{|c|}{10.73} & \\
\hline
\end{tabular}

Note: Means with the same letter are not significantly different

Numbers of stems per plant at 90 and 120 DAP varied significantly in all the locations. At 90 DAP, the highest number of stems per plant was recorded in BARI SP-08 at both the locations (8.17 at Gaibandha and 7.57 at Rangpur) while lowest was recorded in BARI SP-4 at Gaibandha (4.47) and BARI SP-15 at Rangpur (3.83). Similar trends were also observed at 120 DAP at both locations. At 120 DAP, BARI SP-8 produced highest number of stems per plant (8.70 at Gaibandha and 7.83 at Rangpur) followed by local variety at Gaibandha (7.07) and BARI SP-4 at Rangpur (6.33) and the lowest was recorded in BARI SP-4 at Gaibandha (4.93) and BARI SP15 at Rangpur (4.13) (Table 5). 
Table 5. No. of Branches per plant at 90 DAP and 120 DAP of studied OFSP varieties at Gaibandha and Rangpur of Bangladesh during 2019-2020 crop season

\begin{tabular}{|l|l|l|l|l|l|l|}
\hline \multirow{2}{*}{ Variety } & \multicolumn{2}{|l|}{ No. of Stems per Plant at 90 DAP } & \multirow{2}{*}{ Avg. } & \multicolumn{2}{l|}{ No. of Stems per Plant at 120 DAP } & \multirow{2}{*}{ Avg. } \\
\cline { 2 - 3 } \cline { 5 - 6 } & Gaibandha & Rangpur & & Gaibandha & Rangpur & \\
\hline BARI-SP-4 & $4.47 \mathrm{c}$ & $6.03 \mathrm{~b}$ & 5.25 & $4.93 \mathrm{c}$ & $6.33 \mathrm{ab}$ & 5.63 \\
\hline BARI-SP-8 & $8.17 \mathrm{a}$ & $7.57 \mathrm{a}$ & 7.87 & $8.70 \mathrm{a}$ & $7.83 \mathrm{a}$ & 8.27 \\
\hline BARI-SP-12 & $4.73 \mathrm{c}$ & $5.93 \mathrm{~b}$ & 5.33 & $4.97 \mathrm{c}$ & $6.20 \mathrm{~b}$ & 5.59 \\
\hline BARI-SP-15 & $6.13 \mathrm{~b}$ & $3.83 \mathrm{c}$ & 4.98 & $6.37 \mathrm{bc}$ & $4.13 \mathrm{c}$ & 5.25 \\
\hline Local variety & $6.83 \mathrm{ab}$ & $4.30 \mathrm{c}$ & 5.57 & $7.07 \mathrm{~b}$ & $4.60 \mathrm{c}$ & 5.84 \\
\hline Mean & 6.07 & 5.53 & 5.80 & 6.41 & 5.82 & 6.11 \\
\hline CV $(\%)$ & 13.86 & & & 14.90 & \\
\hline
\end{tabular}

Note: Means with the same letter are not significantly different

Foliage coverage (\%) at 90 and 120 DAP showed significant variation among the varieties at both the locations. The variety BARI SP-8 showed the highest foliage coverage at 90 \& 120 DAP in both locations and it was almost 100\%. At Gaibandha, the lowest foliage coverage was observed in BARI SP 15 (38.33\% at 90 and $60.00 \%$ at120 DAP), while in Rangpur the lowest foliage coverage attained in the local variety (31.67\%) at 90 DAP and in BARI SP-15 (53.33\%) at 120 DAP (Table 6).

Considering tuberous roots per plant, there was no significant effect among the varieties at Gaibandha but have significant difference at Rangpur. At Gaibandha, local variety produced the highest number of tuberous root (5.00) followed by BARI SP-4 (4.73), while the lowest was in BARI SP-12 (4.20). At Rangpur, BARI SP- 8 produced the highest number of tuberous root (3.63) followed by BARI SP-12 (3.07) while BARI SP-15 produced the lowest (0.97). All the studied varieties produced higher number of tuberous roots per plant at Gaibandha compare to Rangpur (Table 6). These may be happed due to late planting at Rangpur.

Table 6. Foliage coverage (FC) (\%) at 120 DAP and no. of tuberous root per plant of suited OFSP varieties at Gaibandha and Rangpur district of Bangladesh during 2019-2020 crop season

\begin{tabular}{|c|c|c|c|c|c|c|c|c|c|}
\hline \multirow[t]{2}{*}{ Variety } & \multicolumn{2}{|c|}{$\begin{array}{c}\text { Foliage Coverage } \\
(\%) \text { at } 90 \text { DAP }\end{array}$} & \multirow[t]{2}{*}{ Avg. } & \multicolumn{2}{|c|}{$\begin{array}{c}\text { Foliage Coverage } \\
(\%) \text { at } 120 \text { DAP }\end{array}$} & \multirow[t]{2}{*}{ Avg. } & \multicolumn{2}{|c|}{$\begin{array}{c}\text { No. of Tuberous } \\
\text { roots per plant }\end{array}$} & \multirow[t]{2}{*}{ Avg. } \\
\hline & Gaibandha & Rangpur & & Gaibandha & Rangpur & & Gaibandha & Rangpur & \\
\hline BARI-SP-4 & $80.00 \mathrm{~b}$ & $95.00 \mathrm{a}$ & 87.50 & $96.67 \mathrm{a}$ & $98.33 \mathrm{a}$ & 97.50 & $4.73 \mathrm{a}$ & $3.00 \mathrm{ab}$ & 3.87 \\
\hline BARI-SP-8 & $96.67 \mathrm{a}$ & $100.00 \mathrm{a}$ & 98.34 & $100.00 \mathrm{a}$ & $100.00 \mathrm{a}$ & 100.00 & $4.60 \mathrm{a}$ & $3.63 \mathrm{a}$ & 4.12 \\
\hline BARI-SP-12 & $68.33 c$ & $96.67 \mathrm{a}$ & 82.50 & 93.33 & $100.00 \mathrm{a}$ & 96.67 & $4.20 \mathrm{a}$ & $3.07 \mathrm{ab}$ & 3.64 \\
\hline BARI-SP-15 & $38.33 d$ & $68.33 \mathrm{~b}$ & 53.33 & $60.00 \mathrm{~b}$ & $53.33 \mathrm{c}$ & 56.67 & $4.53 \mathrm{a}$ & $0.97 \mathrm{c}$ & 2.75 \\
\hline Local variety & $81.67 \mathrm{~b}$ & $31.67 \mathrm{c}$ & 56.67 & $93.33 \mathrm{a}$ & $83.33 b$ & 88.33 & $5.00 \mathrm{a}$ & $2.30 \mathrm{~b}$ & 3.65 \\
\hline Mean & 73.00 & 78.33 & 75.67 & 88.67 & 87.00 & 87.83 & 4.61 & 2.59 & 3.60 \\
\hline CV (\%) & & 8.18 & & & 4.73 & & & 15.65 & \\
\hline
\end{tabular}

Note: Means with the same letter are not significantly different

Among the studied varieties, tuberous root length varied significantly at Rangpur but not significantly varied at Gaibandha. At Gaibandha, the root length ranged from 14.83 to $12.87 \mathrm{~cm}$. At Rangpur, the highest root length $(15.93 \mathrm{~cm})$ was found in BARI SP-12 while the lowest $(9.40$ 
$\mathrm{cm}$ ) was recorded in BARI SP-15 (Table 7). There is no significant difference between BRAI SP-4, BARI SP-8(14.50) and local variety $(13.37 \mathrm{~cm})$ at Rangpur. Considering both the locations, average root length varied from $14.85 \mathrm{~cm}$ (BARI SP-12) to $11.80 \mathrm{~cm}$ (BARI SP-4) (Table 7).

There were significant variations among the varieties on tuberous root breadth at both locations. At Gaibandha, the highest root breadth was recorded in BARI SP-12 $(18.60 \mathrm{~cm})$ followed by BARI SP-4 $(17.87 \mathrm{~cm})$ and local variety $(16.30 \mathrm{~cm})$ while the lowest was in BARI SP-15 $(14.23 \mathrm{~cm})$. At Rangpur, the highest root breadth was observed in BARI SP-4 $(18.17 \mathrm{~cm})$ followed by BARI SP-12 $(16.73 \mathrm{~cm})$ and the lowest was found in local variety $(9.63 \mathrm{~cm})$. Considering both the locations, the average breadth of tuberous root were varied from 18.02 to $12.97 \mathrm{~cm}$ (Table 7).

Table 7. Tuberous root Length and Breadth of Sweetpotato at Gaibandha and Rangpur District of Bangladesh during 2019-2020 crop season

\begin{tabular}{|c|c|c|c|c|c|c|}
\hline \multirow{2}{*}{ Variety } & \multicolumn{2}{|c|}{ Tuberous Roots Length $(\mathbf{c m})$} & \multirow{2}{*}{ Avg. } & \multicolumn{2}{|c|}{ Tuberous Roots Breadth (cm) } & \multirow{2}{*}{ Avg. } \\
\cline { 2 - 3 } & Gaibandha & Rangpur & & Gaibandha & Rangpur & \\
\hline BARI-SP-4 & $12.87 \mathrm{a}$ & $10.73 \mathrm{bc}$ & 11.80 & $17.87 \mathrm{ab}$ & $18.17 \mathrm{a}$ & 18.02 \\
\hline BARI-SP-8 & $14.20 \mathrm{a}$ & $14.50 \mathrm{a}$ & 14.35 & $15.70 \mathrm{~cd}$ & $16.07 \mathrm{~b}$ & 15.89 \\
\hline BARI-SP-12 & $13.77 \mathrm{a}$ & $15.93 \mathrm{a}$ & 14.85 & $18.60 \mathrm{a}$ & $16.73 \mathrm{ab}$ & 17.67 \\
\hline BARI-SP-15 & $14.80 \mathrm{a}$ & $9.40 \mathrm{c}$ & 12.10 & $14.23 \mathrm{~d}$ & $12.07 \mathrm{c}$ & 13.15 \\
\hline Local variety & $14.83 \mathrm{a}$ & $13.37 \mathrm{ab}$ & 14.10 & $16.30 \mathrm{bc}$ & $9.63 \mathrm{~d}$ & 12.97 \\
\hline Mean & 14.09 & 12.79 & 13.44 & 16.54 & 14.53 & 15.54 \\
\hline CV $(\%)$ & \multicolumn{2}{|c|}{12.69} & \multicolumn{3}{|c|}{6.21} & \\
\hline
\end{tabular}

Note: Means with the same letter are not significantly different

There was significant effect on tuberous root yield per plant among the varieties at both the locations. At Gaibandha, BARI SP-12 attained the highest tuberous root yield per plant (693.33 gm/plant) followed by BARI SP-8 (626.67 gm/plant). At Rangpur, BARI SP-12 also gave the highest yield $(550.00 \mathrm{gm} / \mathrm{plant})$ followed by BARI SP-8 (533.33 gm/plant) and BARI SP-4 (416.67gm/plant) which was significantly similar to BARI SP- 12 and BARI SP-8. In both locations, BARI SP-15 produced the lowest yield $(408.33 \mathrm{gm} / \mathrm{plant}$ at Gaibandha and 91.66 gm/plant at Rangpur) (Table 8). Considering both the locations, all the varieties given higher yield per plant at Gaibandha compare to Rangpur. The lower yield at Rangpur may be was the result of late planting and comparatively cool weather prevailed during crop growing stage.

Considering tuberous yield per plot, all the varieties showed significant variation at both locations. At both locations, BARI SP-12 produced the highest yield per plot $(35.67 \mathrm{~kg} / \mathrm{plot}$ at Gaibandha and $27.17 \mathrm{~kg} / \mathrm{plot}$ at Rangpur ) followed by BARI SP-8 (28.83 kg/plot at Gaibandha and $23.33 \mathrm{~kg} / \mathrm{plot}$ at Rangpur ) while the lowest was observed in BARI SP-15 (12.00 kg/plot at Gaibandha and $2.77 \mathrm{~kg} / \mathrm{plot}$ at Rangpur $)$ followed by local variety $(21.50 \mathrm{~kg} / \mathrm{plot}$ at Gaibandha and $10.33 \mathrm{~kg} / \mathrm{plot}$ at Rangpur ) (Table 8). These may be happened due to wide range of adaptability of BARI SP-12 which can tolerate more adverse condition like wormer and cooler temperature, on the other hand, BARI SP-15 had lower adaptability that is sensitive to cool temperature of northern Bangladesh conditions. 
Table 8. Tuberous roots yield per plant and yield per plot of studied OFSP varieties at Gaibandha and Rangpur district of Bangladesh during 2019-2020 crop season

\begin{tabular}{|c|c|c|c|c|c|c|}
\hline \multirow{2}{*}{ Variety } & \multicolumn{2}{|c|}{ Tuberous roots yield per plant (gm) } & \multirow{2}{*}{ Avg. } & \multicolumn{2}{|c|}{ Tuberous roots yield per plot (kg) } & \multirow{2}{*}{ Avg. } \\
\cline { 2 - 3 } \cline { 5 - 6 } & Gaibandha & Rangpur & & Gaibandha & Rangpur & \\
\hline BARI-SP-4 & $533.33 \mathrm{bc}$ & $416.67 \mathrm{a}$ & 475.00 & $27.33 \mathrm{~b}$ & $16.50 \mathrm{c}$ & 21.92 \\
\hline BARI-SP-8 & $626.67 \mathrm{ab}$ & $533.33 \mathrm{a}$ & 580.00 & $28.83 \mathrm{~b}$ & $23.33 \mathrm{~b}$ & 26.08 \\
\hline BARI-SP-12 & $693.33 \mathrm{a}$ & $550.00 \mathrm{a}$ & 621.67 & $35.67 \mathrm{a}$ & $27.17 \mathrm{a}$ & 31.42 \\
\hline BARI-SP-15 & $408.33 \mathrm{c}$ & $91.66 \mathrm{~b}$ & 250.00 & $12.00 \mathrm{~d}$ & $2.77 \mathrm{e}$ & 7.38 \\
\hline Local variety & $543.33 \mathrm{~b}$ & $200.00 \mathrm{~b}$ & 371.67 & $21.50 \mathrm{c}$ & $10.33 \mathrm{~d}$ & 15.92 \\
\hline Mean & 561.00 & 336.66 & 459.67 & 25.07 & 16.02 & 20.54 \\
\hline CV $(\%)$ & 16.85 & & \multicolumn{3}{|c|}{11.92} & \\
\hline
\end{tabular}

Note: Means with the same letter are not significantly different

Yield of tuberous roots per hectare varied significantly among the studied varieties in Gaibandha and Rangpur. Due to higher adaptability in northern climate, BARI SP-12 attained the highest yield (39.63 ton/ha) followed by BARI SP-8 (32.03 ton/ha) and BARI SP-4 (30.37 ton/ha) in Gaibandha while the lowest was recorded in BARI SP-15 (13.33 ton/ha). Similar yield trend were also observed in Rangpur where BARI SP- 12 produced the highest yield (30.02 ton/ha) followed by BARI SP-8 (25.93 ton/ha) while, the lowest was recorded in BARI SP-15 (3.03 ton/ha) followed by local variety (11.47 ton/ha). Considering yield in both the locations, all the varieties attained higher yield at Gaibandha than Rangpur (Fig 2). The lower yield at Rangpur may be happened due to late planting.

Considering dry matters percentage of the tuberous roots, significant effect was found in all the varieties at both the locations. At Gaibandha, the highest dry matter was found in BARI SP-12 $(31.40 \%)$ followed by local variety $(29.87 \%)$, while the lowest was recorded in BARI SP-4 $(25.13 \%))$. At Rangpur, BARI SP-12 had the highest dry matter $(30.30 \%)$ followed by BARI SP$8(27.73 \%)$ where BARI SP-4 showed the lowest (25.73\%) (Fig 2). 


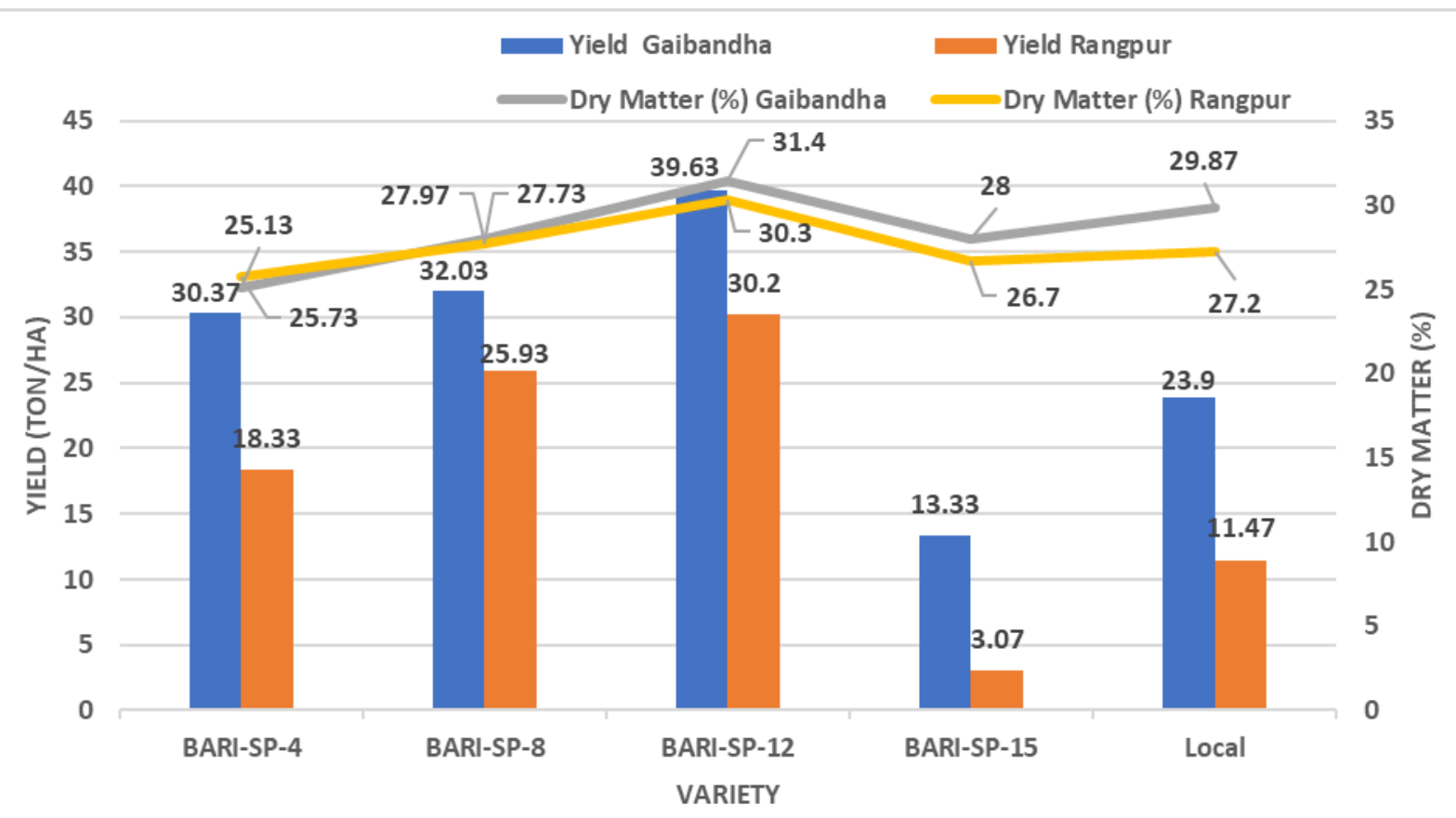

Fig.2. Tuberous root yield and dry matter $(\%)$ of studied OFSP varieties at Gaibandha and Rangpur district of Bangladesh during 2019-2020 crop season

\section{Step-1. Evaluation at the time of vegetative stage}

a) "Gathering and Ranking of Criteria" (vegetative stage)

Fifteen participants ( 5 male, 5 female and researchers and extension staff) were gathered in each location of Gaibandha and Rangpur to evaluate the vegetative stage of the crop. Before evaluation, participants were briefed about the trial objectives. Firstly, participants mentioned some of the criteria which they wanted in the upcoming sweetpotato varieties. All the criteria were listed, and individual voting had been taken for the specific characters. Through voting they have selected disease free variety as first, less insect infestation as second and bushy type plant as third in Gaibandha while in Rangpur, disease resistance scored as first, vigorous plant as second and good taste as leafy vegetables scored as third. (Table 9).

Table 9. Character selection at vegetative stage by the participants at Gaibandha and Rangpur.

\begin{tabular}{|c|c|c|c|c|c|c|}
\hline \multirow{2}{*}{ Criteria } & Men & \multirow{2}{*}{$\begin{array}{l}\text { Order of } \\
\text { Importance }\end{array}$} & Women & \multirow{2}{*}{$\begin{array}{l}\text { Order of } \\
\text { Importance }\end{array}$} & \multirow{2}{*}{$\begin{array}{l}\text { Total } \\
\text { Score }\end{array}$} & \multirow{2}{*}{$\begin{array}{l}\text { Order of } \\
\text { Importance }\end{array}$} \\
\hline & Score & & Score & & & \\
\hline \multicolumn{7}{|c|}{ Gaibandha } \\
\hline Plant should be soft or succulent type & 5 & $\mathrm{~V}$ & 1 & $\mathrm{~V}$ & 6 & $\mathrm{~V}$ \\
\hline Should be taste as leafy vegetable & 8 & IV & 3 & III & 11 & IV \\
\hline Plant should be less insect infestation & 15 & $\mathrm{I}$ & 9 & II & 24 & II \\
\hline Plant should be disease free & 14 & II & 12 & I & 26 & I \\
\hline Plant should be bushy type & 11 & III & 2 & IV & 13 & III \\
\hline Plant should be deep green & 3 & VII & 2 & IV & 5 & VI \\
\hline Plant should be vigorous & 4 & VI & 1 & $\mathrm{~V}$ & 5 & $\mathrm{VI}$ \\
\hline Total & 60 & & 30 & & 90 & \\
\hline
\end{tabular}


International Journal of Agriculture, Environment and Bioresearch

Vol. 5, No. 06; 2020

ISSN: $2456-8643$

\begin{tabular}{|l|c|c|c|c|c|c|}
\hline \multicolumn{7}{|c|}{ Rangpur } \\
\hline Good taste as leafy vegetable & 8 & III & 5 & III & 13 & III \\
\hline Plant should be vigorous & 11 & II & 6 & II & 17 & II \\
\hline Leaf should be small in size & 3 & VIII & 1 & VII & 4 & VIII \\
\hline Plant should be medium in size & 6 & V & 2 & II & 8 & VII \\
\hline Plant should be disease resistance & 16 & I & 5 & III & 21 & I \\
\hline Large leaf area index & 7 & IV & 3 & V & 10 & V \\
\hline Plant should be large in size & 5 & VI & 4 & IV & 9 & VI \\
\hline Vine should be more thick & 4 & VII & 7 & I & 12 & IV \\
\hline Total & $\mathbf{6 0}$ & & $\mathbf{3 0}$ & & $\mathbf{9 0}$ & \\
\hline
\end{tabular}

b) "Ranking of the Preferred Clones by Plot" (vegetative stage)

After selecting the characters, these fifteen participants visited the research field and observed the varieties at vegetative stage. After observing, the participants had given their votes/opinions for specific varieties. According to the voting result (global score), BARI SP-8 ranked first followed by BARI SP-4 and BARI SP- 12 at Gaibandha. While in Rangpur, BARI SP-12 ranked first, BARI SP-4 ranked second and BARI SP-8 ranked third (Table 10).

Table 10. Voting results for selection of clones/variety at vegetative stage by the participants at Gaibandha and Rangpur region.

\begin{tabular}{|c|c|c|c|c|c|c|}
\hline Variety & Score by men & $\begin{array}{c}\text { Order of } \\
\text { importance }\end{array}$ & $\begin{array}{c}\text { Score by } \\
\text { women }\end{array}$ & $\begin{array}{c}\text { Order of } \\
\text { importance }\end{array}$ & Global score & $\begin{array}{l}\text { Order of } \\
\text { ranking }\end{array}$ \\
\hline \multicolumn{7}{|c|}{ Gaibandha } \\
\hline BARI SP-4 & 13 & III & 9 & II & 22 & II \\
\hline BARI SP-8 & 19 & I & 11 & I & 30 & I \\
\hline BARI SP-12 & 16 & II & 6 & III & 21 & III \\
\hline BARI SP-15 & 2 & $\mathrm{~V}$ & 0 & $\mathrm{~V}$ & 2 & $\mathrm{~V}$ \\
\hline Local Variety & 10 & IV & 4 & IV & 14 & IV \\
\hline Total & 60 & & 30 & & 90 & \\
\hline \multicolumn{7}{|c|}{ Rangpur } \\
\hline BARI SP-4 & 18 & II & 8 & II & 26 & II \\
\hline BARI SP-8 & 16 & III & 8 & II & 24 & III \\
\hline BARI SP-12 & 21 & I & 10 & I & 31 & I \\
\hline BARI SP-15 & 1 & $\mathrm{~V}$ & 1 & IV & 2 & $\mathrm{~V}$ \\
\hline Local Variety & 4 & IV & 3 & III & 7 & IV \\
\hline Total & 60 & & 30 & & 90 & \\
\hline
\end{tabular}




\section{Step-2. Evaluation at the time of harvest}

a) "Gathering and Ranking of Criteria" (time of harvest)

At the time of harvesting, again fifteen participants ( 5 men, 5 women and 5 researcher and extension staff) were gathered and initially selected some yield \& yield contributing characters which should have in the upcoming sweetpotato varieties. Then they had given their vote to select the best three criteria. According to voting results, they had selected insect resistant variety as first, good in taste as second and high yield \& medium size root as third in Gaibandha. While in Rangpur, vitamin rich variety got highest votes followed by less insect infestation $\left(2^{\text {nd }}\right)$ and good in taste $\left(3^{\text {rd }}\right)$ (Table 11).

Table 11. Character selection at harvesting stage by the participants at Gaibandha and Rangpur region

\begin{tabular}{|c|c|c|c|c|c|c|}
\hline Criteria & $\begin{array}{l}\text { Score by } \\
\text { Men }\end{array}$ & $\begin{array}{l}\text { Order of } \\
\text { Importance }\end{array}$ & $\begin{array}{l}\text { Score by } \\
\text { Women }\end{array}$ & $\begin{array}{l}\text { Order of } \\
\text { Importance }\end{array}$ & Total & $\begin{array}{l}\text { Order of } \\
\text { Importance }\end{array}$ \\
\hline \multicolumn{7}{|c|}{ Gaibandha } \\
\hline High yielding & 13 & II & 1 & $\mathrm{~V}$ & 14 & III \\
\hline Insect resistance variety & 15 & $\mathrm{I}$ & 6 & III & 21 & I \\
\hline Nice to look at & 3 & VI & 5 & IV & 8 & $\mathrm{~V}$ \\
\hline Medium in size & 7 & $\mathrm{~V}$ & 7 & II & 14 & III \\
\hline Good in taste & 9 & IV & 9 & I & 18 & II \\
\hline High storage capacity & 10 & III & 1 & $\mathrm{~V}$ & 11 & IV \\
\hline Disease free variety & 3 & VI & 1 & $\mathrm{~V}$ & 4 & VI \\
\hline Total & 60 & & 30 & & 90 & \\
\hline \multicolumn{7}{|c|}{ Rangpur } \\
\hline Skin don't crack after boil & 1 & VIII & 0 & VIII & 1 & VIII \\
\hline Good in taste & 7 & IV & 7 & II & 14 & III \\
\hline Vitamin rich & 14 & II & 10 & $\mathrm{I}$ & 24 & $\mathrm{I}$ \\
\hline Red skin & 4 & VII & 1 & VII & 5 & VII \\
\hline High yield variety & 8 & III & 4 & III & 12 & IV \\
\hline High storage capacity & 6 & $\mathrm{~V}$ & 4 & $\mathrm{~V}$ & 10 & $\mathrm{~V}$ \\
\hline Less insect infestation & 15 & $\mathrm{I}$ & 3 & IV & 18 & II \\
\hline Medium in size & 5 & VI & 1 & VI & 6 & VI \\
\hline Total & 60 & & 30 & & 90 & \\
\hline
\end{tabular}

b) "Ranking of the best variety by farmers" (time of harvest)

After selecting the characters, these participants were observed the harvested tuberous roots in the field and were taken part in the selection process considering the traits of good yield, skin color, uniformity, good shape \& size, marketable roots and disease resistance etc. According to global score of voting results, BARI SP-12 ranked first, BARI SP-8 second and BARI SP-4 ranked third at Gaibandha region. While in Rangpur region, BARI SP-12 ranked first, BARI SP4 second and BARI SP-8 ranked third. (Table 12). 
Table 12. Voting results for clones/varieties selection at harvesting stage by the participants at Gaibandha and Rangpur region.

\begin{tabular}{|c|c|c|c|c|c|c|}
\hline Variety & Score by men & $\begin{array}{c}\text { Order of } \\
\text { importance }\end{array}$ & $\begin{array}{c}\text { Score by } \\
\text { Women }\end{array}$ & $\begin{array}{c}\text { Order of } \\
\text { importance }\end{array}$ & Global score & $\begin{array}{l}\text { Order of } \\
\text { ranking }\end{array}$ \\
\hline \multicolumn{7}{|c|}{$\begin{array}{l}\text { Gaibandh } \\
\text { a }\end{array}$} \\
\hline BARI SP-4 & 16 & II & 7 & III & 23 & III \\
\hline BARI SP-8 & 15 & III & 9 & II & 24 & II \\
\hline BARI SP-12 & 22 & I & 11 & I & 33 & I \\
\hline BARI SP-15 & 0 & $\mathrm{~V}$ & 1 & V & 1 & $\mathrm{~V}$ \\
\hline Local Variety & 7 & IV & 2 & IV & 9 & IV \\
\hline Total & 60 & & 30 & & 90 & \\
\hline \multicolumn{7}{|c|}{ Rangpur } \\
\hline BARI SP-4 & 19 & II & 8 & III & 27 & II \\
\hline BARI SP-8 & 17 & III & 9 & II & 26 & III \\
\hline BARI SP-12 & 21 & I & 11 & I & 32 & I \\
\hline BARI SP-15 & 0 & $\mathrm{~V}$ & 0 & $\mathrm{~V}$ & 0 & $\mathrm{~V}$ \\
\hline Local Variety & 3 & IV & 2 & IV & 5 & IV \\
\hline Total & 60 & & 30 & & 90 & \\
\hline
\end{tabular}

\section{Step-3. Organoleptic Evaluation}

After completing harvesting stage evaluation, participants were participated in the organoleptic evaluation program of the studied sweetpotato varieties at Gaibandha and Rangpur separately. At Gaibandha, considering mean appearance of the roots, flesh color, taste, presence of fiber and flesh texture of each variety, BAR SP-4 ranked first (following a scale of 1-5, where 1= very bad, 2=bad, 3=Fair, 4=Good, 5=Excellent) followed by BARI SP-12 on the other hand farmers' choice was the poorest to local variety. Similar trend also found in Rangpur (Fig.3).
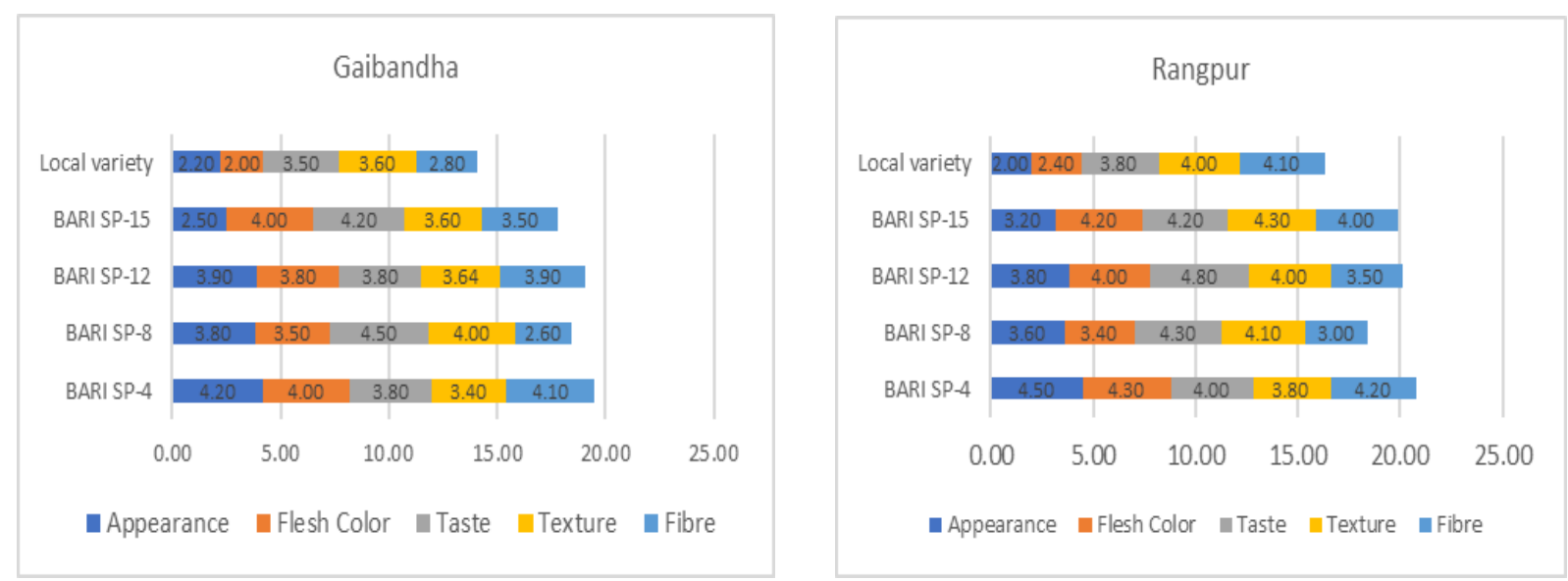

** Overall Scale: 5-Very good; 4-Good; 3-Fair; 2-Bad and 1-Very bad

Fig 3. Organoleptic evaluation test performance of the varieties at Gaibandha and Rangpur region 
Vol. 5, No. 06; 2020

ISSN: $2456-8643$

\section{CONCLUSION}

From the above studies, it was observed that BARI SP-12 performed well in northern district compare to other varieties. Considering vegetative and harvesting stage evaluation participants' (farmers and researchers) choice also went to BARI SP-12 at both locations. But in organoleptic evaluation, participants preferred BARI SP-4 as the best one followed by BARI SP-12. Considering overall performance of the studied varieties, it may be concluded that BARI-SP-12 and BARI SP-8 have higher adaptability under northern districts and BARI SP-15 is very sensitive to cooler weather which is not well adapted in these areas.

\section{Acknowledgement}

The author expresses his deep sense of gratitude to UKAID for providing financial supports through DDBIO Project for conducting the present experiment in Rangpur and Gaibandha districts. The author is also thankful to the authority of Tuber Crop Research Centre (TCRC) of Bangladesh Agricultural Research Institute (BARI) for their help in supplying vines for conducting the study.

\section{REFERENCES}

Ahmed, M.D.S., M.A. Quadir, M.K.R. Bhuiyan and T.R. Dayal, 1998. Genetic diversity of sweet potato (Ipomoea batatas (L.) Lam). Bangladesh J. Root Crops, 24: 11-15.

Anonymous, 2020. Sweetpotato facts and Figures. https://cipotato.org/sweetpotato/sweetpotatofacts- and-figures/

Anonymous, 2015. IMF Country Report. Bangladesh Poverty Reduction Strategy Paper 20112015 (PRSP- II), P. 387. Or www.imf.org/external/pubs/ft/scr/2013/cr1363.pdf

National Institute of Population Research and Training (NIPORT), Mitra and Associates, and ICF International. 2016. Bangladesh Demographic and Health Survey 2014. Dhaka, Bangladesh, and Rockville, Maryland, USA: NIPORT, Mitra and Associates, and ICF International. 354p.

Bdnews, 2019.https://bdnews24.com/economy/2019/10/16/bangladesh-ranks-88th-on-hungerindex-above- india

CIP-Centro Internacional de la Papa. 2008. Sweetpotato (I. batatas). www.cipotato.org/sweet potato.

Delowar, H.K.M. and M.A. Hakim, 2014. Effect of salinity levels on the morpho-physiological characteristics and yield attributes of sweet potato genotypes. Int. J. Sci. Res., 10: 929934.

Delowar, H.K.M. and M.A. Hakim, 2014. Effect of salinity levels on the morpho-physiological characteristics and yield attributes of sweetpotato genotypes. Int. J. Sci. Res., 10: 929934. 
FAO, 2010. Nutrition Country profile Bangladesh. http://www.fao.org/ag/agn/nutrition/bgd_en. stm

icddr'b, (2020). A brief guide to malnutritionand its impact globally and in Bangladesh.

https://www.icddrb.org/news-and-events/press-corner/media-resources/malnutrition

Karim, K.M.R and T. Tasnim, 2015. Nutritional Status, Dietary Food and Nutrient Consumption Patterns in Monga Affected Area of the Northern Part of Bangladesh. Asian J.Cli. Nut., 7: 55-63.

Otoo, J.A., A. Missah and A.G. Carson, 2001. Evaluation of sweetpotato for early maturity across different agro-ecological zones in Ghana. Afr. Crop Sci. J., 9: 25-32.

Rahaman E.H.M.S, A.A. Mahmud, M. Hossain, H.C. Mohanta, M.A. Rahman, M.S.I. Khan, M.E. Haque, M.M. Hossain, M.M. Hasan and B. Merideth, 2015. Field performance of sweet potato varieties in saline zone of Bangladesh. Bangladesh Hort., Vol.1 No. 1\&2 (Series-2): 67-76, 2015

Rahaman E.H.M.S., M.M. Hossain, M.E. Hoque, M.R. Ali, A.A. Mahmud, M.M. Hasan, H.C. Mohanta, M.K.R Bhuiyan, M.S. Islam and M.J. Hossain, 2016. Farmers' preference and suitability assessment of BARI released orange-fleshed sweet potato varieties in charlands of Gaibandha. Bangladesh Hort., 2(2) (Series 2):1-11.

Vimala, B. and P.G. Rajendra, 1998. "Sree Retha" and Sree Bhadra"-two promising short duration varieties of sweet potato. J. Root Crops, 24(1): 25-30.

Wangchuk, P., S. De Haan and R. Dochen. 2015. A Guide to Conduct Participatory Varietal Selection using Mother and Baby Trial Design in Potato. Dept. of Agriculture, Ministry of Agriculture and Forests, Thimphu, Bhutan. 38p. 